\title{
FEATURES OF DIAMOND AND ITS INDICATOR MINERALS OF KIMBERLITES OF THE M.V. LOMONOSOV DEPOSIT, ARKHANGELSK REGION, RUSSIA
}

\author{
A.V. Bovkun ${ }^{1}$, G.Yu. Kriulina ${ }^{1}$, V.K. Garanin'², V.V.Tretyachenko ${ }^{3}$ \\ ${ }^{1}$ M.V.Lomonosov Moscow State University, Moscow, Russia, bovkun2004@mail.ru, galinadiamond@gmail.com \\ ${ }^{2}$ A.E. Fersman Mineralogical Museum of RAS, Moscow, Russia, vgaranin@mail.ru \\ ${ }^{3}$ PJSC ALROSA, Archangelsk, Russia, TretyachenkoVV@severalmaz.ru
}

\section{Introduction}

The M.V. Lomonosov diamond deposit, Arkhangelsk region, NW Russia consists of six kimberlite pipes, forming $9.5 \mathrm{~km}$ length cluster within the Zolotitskoe Kimberlitic Field. These pipes are composed of the same type petrography varieties of kimberlitic rocks, but based on a number of geological and diamond features this cluster divided into Northern (M.V. Lomonosova, Pomorskaya, Pionerskaya and Karpinskogo-2 pipes) and Southern (Karpinskogo-1, Archangelskaya) Groups (Fig. 1a). The diamond grade in main types of ore - tuffisitic (autolithic) kimberlites of the Southern Group kimberlite pipes is higher (1.2-1.5 ct/t) than in the Northern Group (0.4-0.7 ct/t). Pomorskaya pipe reserves with low diamond grade ores $(<0.1 \mathrm{ct} / \mathrm{t})$ estimated as resources presently, because the mining of this pipe is unecomical presently.
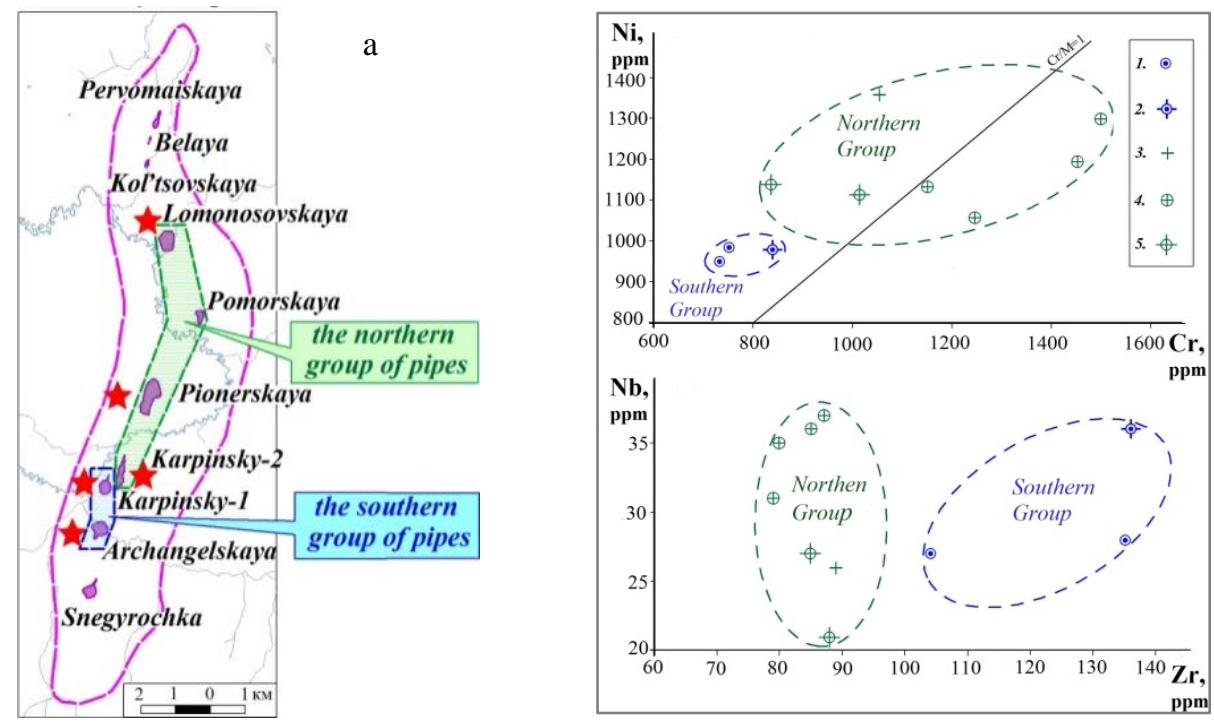

Figure 1: Zolotitskoe Field and M.V. Lomonosov diamond Deposit scheme (a); $\mathrm{Cr}-\mathrm{Ni}$ и $\mathrm{Zr}-\mathrm{Nb}$ contents for tuffisitic (autolithic) kimberlites of the Southern (1 - Archangelskaya, 2 - Karpinskogo-1) and Northern (3 Karpinskogo-2, 4 - Pionerskaya, 5 - Lomonosova) Groups’ pipes of the M.V. Lomonosov deposit (Parsadanyan et al., 1996).

The results of present study revealed differences in the chemical composition of diamond indicator minerals (DIMs), morphology, optical properties, internal structure, defect-impurity composition and diamond quality of the Northern and Southern Groups' pipes. The relationship between the diamond characteristics and matter features, diamond grade of main types of diamond-bearing kimberlitic ores was indicated.

\section{Analytical Results}

Autholitic kimberlites (AK) of the Southern Group pipes with higher diamond grade are characterized by lower chromium and nickel contents (Fig. 1b) and higher zirconium, strontium, thorium, hafnium contents in comparison with similar rocks of the Northern Group pipes (Parsadanyan et al., 1996). 
There are sharply low DIMs (pyrope, chromite and clinopyroxene) content in the Northen Group pipes. In AK of the Southern Group pipes the total number of DIMs is 0.097-0.133 kg/t, and in AK of the of the Northern Group pipes is $0.035-0.079 \mathrm{~kg} / \mathrm{t}$.

DIMs (pyrope, chromite and clinopyroxene) of Northern Group pipes presented by higher chromium varieties corresponding to high-pressure depth subfacies compare to kimberlites of the Southern Group pipes. Pyropes (>5 wt.\% $\mathrm{Cr}_{2} \mathrm{O}_{3}$ ) are mostly identified in the Pionerskaya (86\%) and Karpinskogo-2 (74\%) pipes (Northern Group pipes), with lower presence in the Archangelskaya (30\%) and Karpinskogo-1 (16\%) pipes (Southern Group). Chromite content (60 wt.\% $\mathrm{Cr}_{2} \mathrm{O}_{3}$ ) in the Pionerskaya (40\%) and Karpinskogo-2 (34\%) pipes is sharply higher than in Archangelskaya $(<11 \%)$ and Karpinskogo-1 (17\%) pipes, where chromite with 55-60 wt.\% $\mathrm{Cr}_{2} \mathrm{O}_{3}$ is mostly presented (30-33\% of total).

However, there is higher content of Cr-spinels and pyropes with higher Ti-content in Northern Group kimberlites in compare with the Southern Group. Chromites with $\mathrm{TiO}_{2}>3$ wt.\% distributed in the Pionerskaya (14\%), Karpinskogo-2 (9\%), Pomorskaya (11\%) pipes (Northern Group), with lower presence ( $\sim \%)$ in Southern Group pipes. The shares of pyrope with $\mathrm{TiO}_{2}>0,4$ wt.\% for Pionerskaya and Karpinskogo-2 pipes are $24 \%$ and 10,5\% respectively, but only $4-5 \%$ for the Southern Group pipes.

A significant proportion of the pyropes from Northern Group kimberlites also have higher content of $\mathrm{Zr}$ (62\% grains with $\mathrm{Zr}>30 \mathrm{ppm}$ ), $\mathrm{Y}$ and Ga (Sablukov et al., 2009). The collection obtained and published data indicates: the lower diamondiferous kimberlites of the Northern Group related with intensive exposure to the lithospheric mantle by melting metasomatic processes, which caused the destruction of a large part of diamonds in the process of dissolution and a significant increase of the dodecahedrons proportion, especially in large classes.

Despite the low diamond content in the Northern Group pipes, qualitative characteristics of diamond ores are significantly higher in many indicators than for Southern Group pipes. Ultrabasic paragenesis colorless diamonds with high degree of transparency and fiber growth mechanism are dominated in the Pionerskaya and Pomorskaya pipes. Dodecahedrons with high etching and corrosion degree are prevailing. Diamonds have a low content of hydrogen impurity with a large values range. The distribution maximum of $\mathrm{CH}$-centers is identified at $0-5 \mathrm{~cm}^{-1}$, and for the diamonds of the Southern Group pipes at 3-10 $\mathrm{cm}^{-1}$ (Fig. 2b). The Northern Group pipes' diamonds characterized by high presence of nitrogen impurities concentrations (Fig. 2a), and structural centers associated with plastic deformation. Unlike the Southern Group pipes' diamonds, the structural nitrogen is considerably higher aggregated (two maximum allocation $\% \mathrm{~N}_{\mathrm{B}}=10-14$ and $\% \mathrm{~N}_{\mathrm{B}}=40-55$ according to IRspectroscopy data; centers $\mathrm{P} 2$ and $\mathrm{N} 2$ are presented according to EPR), indicating more prolonged exposure in high temperature conditions contributing to oxidative dissolution. Generally, near gem diamonds prevalent (65-70\%) in the Pionerskaya pipe. The quality of the Pomorskaya pipe diamonds is significantly lower because of widespread intergrowths and individuals with a low degree of safety, deep etched channels and numerous graphite inclusions.

According to received data, there is lower quality of diamonds in the Southern Group pipes, which is due to inherently defective structure of crystals. The dominant share $(60 \%)$ of diamonds in the Archangelskaya and Karpinskogo-1 pipes is presented by industrial diamonds. The share of gemquality diamonds is about $25 \%$. There are mostly dodecahedral and tetrahexahedral diamonds with zonal-sectorial structure and high degree of internal tension with lots of cracks, graphite and fluid inclusions. The tetrahexahedral content in all size-classes is $14-27 \%$, but only $5-13 \%$ in the Northern Group pipes. Upon that, diamonds of high-nitrogen groups (Fig. 2a) with low degree of defects aggregation are mostly presented there. It is evidence of lower temperatures at genesis of crystals majority and short time post-crystallization annealing. According to FTIR data a large proportion of the Archangelskaya and Karpinskogo-1 pipes diamonds belong to eclogitic paragenesis. 
There is a sharp increase in the octahedrons concentration in a small size-class $(-1+0.5 \mathrm{~mm})$ identified: $20 \%$ for the Northern Group pipes, and 15-17\% for the Southern Group pipes (Makhin et al., 1990).
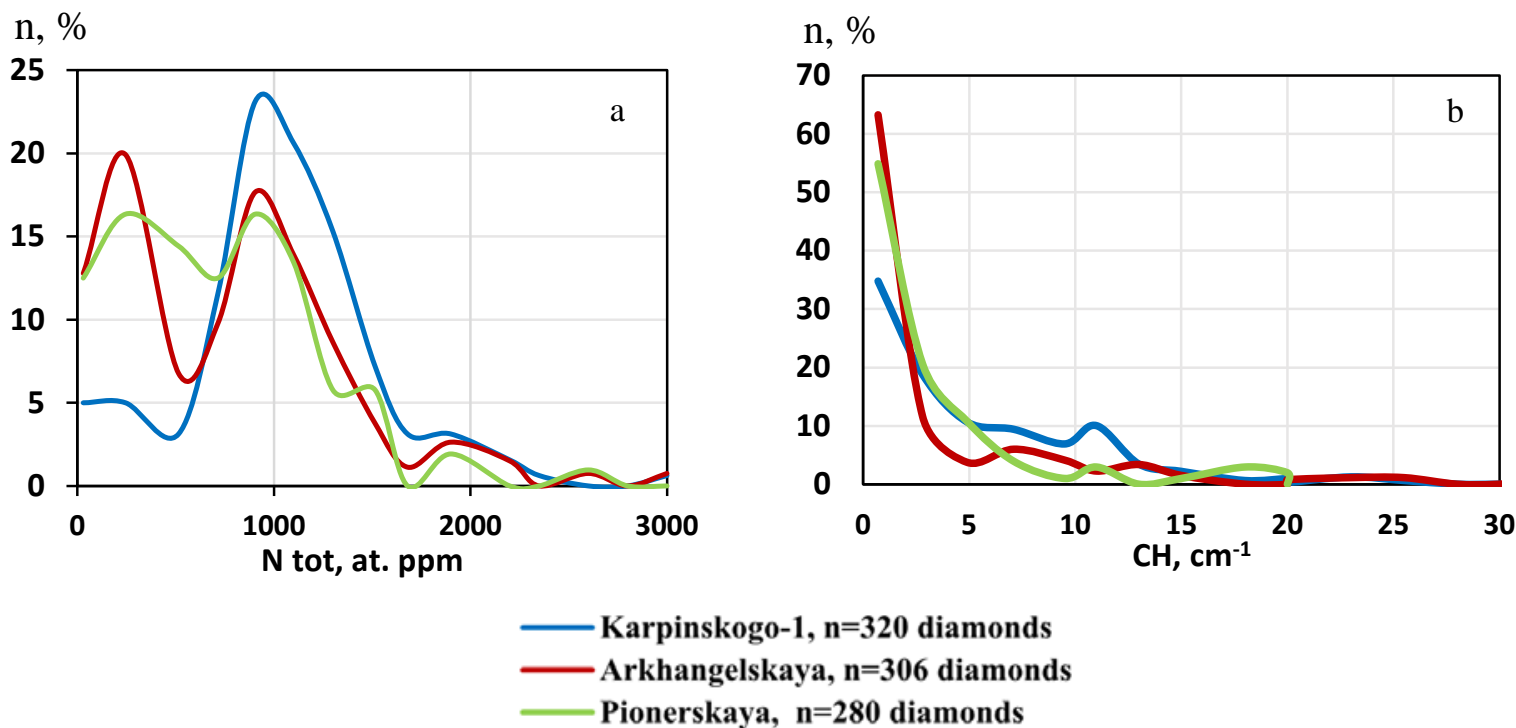

Figure 2: Distribution of diamonds with different total concentration of the defective-impurity centers of nitrogen (Ntot) (a), and with different ratio of the absorption of impurity hydrogen centers $\mathrm{CH}\left(3107 \mathrm{~cm}^{-1}\right)(\mathrm{b})$ in the South (Karpinskogo-1 and Archangelskaya) and Northern (Pionerskaya) Group pipes of the M.V. Lomonosov diamond deposit

\section{Conclusion}

Thus, a significantly higher degree of diamond grade in main types of ore - tuffisitic (autolithic) kimberlites of the Archangelskaya and Karpinskogo-1 pipe in connection with the kimberlitic rocks of the Karpinskogo-2 and Pionerskaya pipe is due to lower degree of impact processes of melt of mantle metasomatism, which mostly processed in relation to Northern Group kimberlites. In addition, there is significant higher proportion of eclogitic paragenesis diamonds in most productive Southern Group kimberlites. The common lower diamond quality in the Southern Group pipes is mainly due to more defective crystal structure, which is probably associated with deeper degree differentiation of the initial hypogene substance.

\section{References}

Makhin AI, Bartoshinsky ZV, Bekesha SN, Vinnichenko TG, Voloshinovsky AS, Vesilov VV (1990) Technical report: to study of main typomorphic features of diamonds from Zolotitskoe Field kimberlites for for the purposes of classification, to develop and implement a methodology for integrated study of diamonds in terms of the expedition. Archangelsk. In Russian

Parsadanyan KS, Kononova VA, Bogatikov OA (1996) Sources of the heterogeneous magmatism of the Arkhangelsk diamond-bearing province. Petrology, 4 (5): pp. 496-517. In Russian

Sablukov SM, Sablukova LI, Griffin WL (2009) Distribution of rare elements in deep kimberlitic minerals as a feature of plume processes in the North part of the Russian Platform. In: Proc. IX Int. Conf. on Deep-seated magmatism, its sources and plumes, Miass, pp. 135-170. In Russian 